\title{
Post-dural puncture headache
}

This article was published in the following Dove Press journal:

International Journal of General Medicine

10 January 2012

Number of times this article has been viewed

\author{
Ahmed Ghaleb' \\ Arjang Khorasani ${ }^{2}$ \\ Devanand Mangar ${ }^{3}$ \\ 'Department of Anesthesiology, \\ University of Arkansas for \\ Medical Sciences, Little Rock, AR, \\ ${ }^{2}$ Anesthesiology Residency Program, \\ Advocate Illinois Masonic Medical \\ Center, Chicago, IL, ${ }^{3}$ Florida Gulf to \\ Bay Anesthesiology, Tampa General \\ Hospital, Tampa, FL, USA
}

\begin{abstract}
Since August Bier reported the first case in (PDPH) has been a problem for patients following d 1 puncture. flinical and laboratory research over the last 30 years has shown that use sma rr-gaug heedles, particularly of the pencil-point design, are associated with a lo risk $\mathrm{PD}$ an traditional cutting point needle tips (Quincke-point needle). A carefull tor can rule out other causes of headache. A postural component of headache is the qua no $\mathrm{PD}$. In high-risk patients $<50$ years, post-partum, in the event a large-ga on dle punctu is initiated, an epidural blood patch should be performed within 24-48 hours of do 1 puncture. The optimum volume of blood has been shown to be 12-20 mL adult patients. Oomplications caused by autologous epidural blood patching (AEBP) are $n$ e.

Keywords: post-dural punctus headach, gauge, needles, cause, risk, incidence

\section{Introduction}

Post-dur pun ure h adache (PDPH) is an important iatrogenic cause of patient morbic $\mathrm{V}$ in manesthesia, pain mant after attempted epidural blocks after $\mathrm{s}$, nal taps. The incidence of dural puncture ranges from $0.16 \%-1.3 \%$ in $\mathrm{Cx}_{\mathrm{P}}$ rienced ha ds. ${ }^{1}$ Post-dural puncture headache develops in $16 \%-86 \%$ of cases after attemp d epidural block with large bore needles. ${ }^{2}$

Any breach in the dura may result in PDPH. A breach can be either iatrogenic or sportaneous. Performing an epidural or spinal anesthetic or a diagnostic myelogram produce the very distinctive PDPH. It can occur immediately or as long as 48 hours post-procedure.
\end{abstract}

Spontaneous intrathecal CSF leaks (SIH) leading to headache are rare, with a prevalence of approximately 1:50,000 persons, and are more common in women, with a female-male ratio of $3: 1$. Spontaneous intracranial hypotension is usually seen in the cervical-thoracic region and is also associated with co-morbidities like Marfan's syndrome, neurofibromatosis, connective tissue disorders and Ehlers-Danlos syndrome.

The International Headache Society recognizes the absence of a definitive pain

Correspondence: Ahmed Ghaleb University of Arkansas for Medical Sciences, 430I West Markham,

Slot 5 15, Little Rock, AR 72205, USA

Tel + I 50I 68688 I8

Fax + I 50I 5264216

Email ghalebahmed@uams.edu description for the headache associated with SIH. In its criteria of 1998, the International Headache Society classify low CSF pressure, which includes CSF fistula headache: "Posttraumatic, postoperative or idiopathic fluid leak demonstrated by measurement of glucose concentration in leaking fluid, or by leakage of spinally injected dye or radioactive tracer" with characteristics of post-lumbar puncture headache. 
According to the International Headache Society, the criteria for a low CSF pressure $\mathrm{PDPH}^{3,4}$ include a headache that develops less than 7 days after a spinal puncture, occurs or worsens less than 15 minutes after assuming the upright position and improves after less than 30 minutes in the recumbent position. The headache should disappear within 14 days after a spinal puncture; if it persists it is called a CSF fistula headache.

\section{History}

The history of spinal anesthesia can be traced back to the late 1800s when Wynter and Quincke aspirated cerebrospinal fluid from patients with tuberculous meningitis in an attempt to lower intracranial pressure. ${ }^{5}$ August Bier performed spinals on himself and eight other subjects using 10-15 mg of cocaine. Four of the nine people, including Professor Bier, developed PDPH. ${ }^{6}$

\section{Anatomy and pathophysiology}

Anatomically, the spinal dura mater extends from the foramen magnum to the second segment of the sacrum. It consists of a dense connective tissue matrix of collagen and elastic fibers. The average adult produces about $500 \mathrm{~mL}$ of CSF per day, or $21 \mathrm{~mL}$ per hour $(0.3 \mathrm{~mL} / \mathrm{kg} / \mathrm{hr})$, with $90 \%$ coming from the choroid plexus, and $10 \%$ from the br substance itself. A total of about $150 \mathrm{~mL}$ of CSF circulat at any one time and is absorbed by the arachno the cause of PDPH is not entirely certain. The b expl ation is that low CSF pressure results from CS leak througn a dural or arachnoid tear; a leakage th xceeds th rate of CSF production. ${ }^{4}$ As little as $10 \%$ loss of SF volume can cause an orthostatic headache. T ere are two bas theoretical mechanisms to explain PDK On is reflex vasodilatation of the meningeal vessel re to re loy CSF pressure. The other is traction the ain-se ave intracranial structures in the upright sit r. Tm then on the uppervical nerves including $\mathrm{C} 1, \mathrm{C} 2$, nd $\mathrm{C} 3$, causes pain in the neck and shoulders. Traction on the mith cranial nerve causes a frontal headache. Traction on the sixth cranial nerve causes visual symptoms. Pain in the occipital region is due to the traction of the ninth and tenth cranial nerves.

\section{Needle size and incidence of PDPH}

The incidence of PDPH is directly related to the needle diameter that pierces the dura mater. ${ }^{7}$

Diagnostic lumbar puncture (LP) requires 22-gauge needles to facilitate measurement of opening pressure and withdrawal of CSF over a reasonably brief time period.
With needles smaller than size 22-gauge, collection of $2 \mathrm{~mL}$ of CSF may take 6 minutes or longer and measurement of CSF pressure may be less accurate. ${ }^{8}$ An addendum to the American Academy of Neurology (AAN) practice guidelines advocated the use of 22-gauge needles, but reported a case series where 25 -gauge needles were used successfully. ${ }^{9}$

Although smaller diameter needle punctures used for subarachnoid block decrease the risk of PDPH, these needles are technically difficult to use and are associated with a lower success rate in spinal anesthesia, ${ }^{10}$ especially in inexperienced hands. This is due to failure to recognize dural puncture secondary to slow flow through a small needle, leading to multiple and repeated puncture attempts. The incidence of PDPH with the 25-gauge Whitacre (non-cutting) needle is less than with the 27-ga ge Q ncke (cutting) needle. Morbidity associated wit umbar pun ture can be decreased by the proper selecti of an pprop ate needle gauge and needle tip config ation

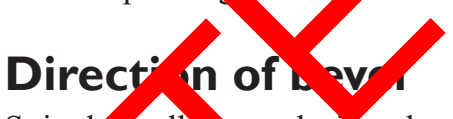

Spinal reedla are designed as cutting bevels, as in the Qy are-type, onencil point, as in the Whitacre-type s inal need'e. Dural fibers were once believed to run 1. gitudinal $; ;^{13}$ however microscopic dissection of the dura mato cadavers revealed that dural fibers do not run ondinally or in a parallel fashion. The dura is a laminated structure built up from well-defined layers oriented concentrically around the medulla spinalis. ${ }^{14}$ Orienting the bevel of a cutting needle probably needs further consideration before making absolute, blanket statements regarding the etiology of dural puncture leaks. The use of a paramedian approach to the subarachnoid space has been suggested as a means of reducing PDPH particularly when using cutting needles. ${ }^{15}$

Electron microscopy has shown that pencil point needles are more traumatic to the dura than the cut bevel needles. It is postulated that a pencil point needle produces an irregular tear in the dura and the subsequent inflammatory reaction reduces CSF leakage more effectively than the clean U-shaped puncture seen with a cutting-bevel needle, which decreases the risk of PDPH. ${ }^{16}$

\section{Dura mater and response to trauma}

After perforation of the dura there will be leakage of CSF. In neurosurgical experience even minor perforations need to be closed, either directly or through the application of synthetic or biological dural graft material. Failure to close the dural perforation may lead to adhesions, continuing CSF 
leak, and the risk of infection. It was thought that the closure was facilitated through fibroblastic proliferation from the cut edge of the dura. Work published in $1959^{17}$ dismissed the notion that the fibroblastic proliferation arose from the cut edge of the dura. This study maintained that the dural repair was facilitated by fibroblastic proliferation from surrounding tissue and blood clots. The study also noted that dural repair was promoted by damage to the pia arachnoid, the underlying brain and the presence of blood clots. It is therefore possible that a spinal needle carefully placed in the subarachnoid space does not promote dural healing, as trauma to adjacent tissue is minimal. Indeed, the observation that blood promotes dural healing agrees with Gormley's original observation that bloody taps were less likely to lead to a post-dural puncture headache as a consequence of a persistent CSF leak. ${ }^{18}$

\section{Symptoms}

PDPH typically manifests as a postural, frontal, frontotemporal, or occipital headache, worsened by ambulation and improved by assuming the decubitus position, occurring within 48 hours after dural puncture. The accompanying symptoms are usually nausea, vomiting and neck stiffness. ${ }^{1,19}$ Atypical symptoms after accidental dural puncture have been infrequently described.

Other nonspecific symptoms may occur such as sea, vomiting, ocular complaints such as photophob and diplopia, and auditory complaints like tim and hyperacusis. The first case of diplopia after aral py cture was reported by Quincke more than 100 ye $\mathrm{s}$ ag or extraocular muscle paralysis (EOM ${ }^{5}$, fter dura, uncture has been reported occasionally, primarily the neurology and ophthalmology literature. ecause there $\mathrm{m}$. to be a window period before diplo, a ma fests after dural puncture, the patient and ph - ian y not ways believe that the symptom is sec ndary o duro uncture, particularly when it occurs after astorn PDP. Diplopia usually occurs 4-10 days after yral puncture but can manifest as late as 3 weeks. Full recoviry can generally be expected in 2 weeks to 8 months, although permanent cases have rarely been reported. ${ }^{20}$

\section{Factors influencing incidence}

Women, particularly during pregnancy and especially after vaginal delivery, are considered at increased risk for PDPH. The incidence of PDPH is highest between 18 and 30 years of age and declines in children younger than 13 years and adults older than 60 years. The incidence is greater in patients with lower body mass index. ${ }^{2}$ Women who are obese or morbidly obese may actually have a decreased incidence of PDPH. The decreased incidence is due to the increase in intra-abdominal pressure which may act as an abdominal binder helping to seal the defect in the dura and decreasing the loss of CSF. Younger women may be at a greater risk because of increased dural fiber elasticity that maintains a patent dural defect compared to a less elastic dura in older patients. ${ }^{4}$ Patients with a headache before lumbar puncture and a prior history of PDPH are also at increased risk. There is no known relationship between the diagnosis of migraine headaches and increased incidence of PDPH after regional anesthesia. ${ }^{21}$ There may be some correlation between a history of motion sickness and PDPH. Another important factor is the experience of the person doing the procedure leading to the puncture of the dura. Co nuon spinal infusion reduced the incidence of PDPH w n compar to single shot spinal, at least according to ne stur

\section{Differentia dignosis}

A compre ssive hist $\mathrm{v}$ a physical exam must be carried out before ma ng the dragnosis of PDPH. Spinal abscess, spi arematoma, eptic or aseptic meningitis, intracranial ass lesion cerebral aneurysm, cerebral edema, myofascial s. drome, a chnoiditis caused by intrathecal steroids, transien ologic syndrome or related symptoms, unspecific and dural puncture lumbalgia, neural toxicity of the drugs, and anterior spinal artery syndrome, post-partum cerebral angiopathy and cerebral thrombophlebitis should all be ruled out. ${ }^{10,23,24}$ Additional tests such as a cerebral CT scan, or magnetic resonance imaging could be performed in cases with atypical post-dural puncture symptoms, to exclude the possibility of developing serious complications. ${ }^{25}$

Few cases of atypical post-dural puncture symptoms have been reported in the literature. Lybecker et al cited interscapular pain as a "related musculoskeletal symptom," however; no instances of upper back pain are cited among the 75 cases of PDPH reported by the authors. ${ }^{19}$ McGrady and Freshwater reported a case of posterior neck pain without headache after spinal anesthesia. ${ }^{26}$ Schabel et al reported a case of arm pain with dysesthesia after an unintended dural puncture, and explained it as irritation of the $\mathrm{C} 5$ and $\mathrm{C} 6$ nerve roots caused by central traction. ${ }^{24}$

\section{Treatment}

\section{Conservative/symptomatic therapy}

The treating clinician must provide emotional support and reassurance to patients with PDPH. Bed rest has been advocated in cases of dural puncture by some clinicians. 
However, a recent meta-analysis failed to show that bed rest after dural puncture was better than immediate mobilization in reducing the incidence of $\mathrm{PDPH} .{ }^{27}$ Bed rest can be associated with a higher incidence of PDPH in particular patient groups. ${ }^{28}$ Bed rest may postpone the occurrence of the headache but does not prevent it.

\section{Pharmacotherapy}

Oral and intravenous medications

Oral hydration remains a popular therapy for PDPH, but there is no evidence that vigorous hydration has any therapeutic benefit, or that it encourages an increased production of cerebrospinal fluid. However, no patient with PDPH should be allowed to become dehydrated.

The efficacy of oral caffeine for the treatment of PDPH was evaluated in 40 postpartum patients. ${ }^{29} \mathrm{~A}$ single oral dose was demonstrated to be safe, effective and should be considered in the early treatment of mild PDPH. Caffeine sodium benzoate, as an intravenous bolus or an infusion can be used to treat PDPH. Caffeine was $75 \%$ to $80 \%$ effective in the initial treatment of PDPH; however, follow-up 48 hours later revealed that all patients had a return of their headache. ${ }^{30}$

Cosyntropin, a synthetic form of adrenocorticotropic hormone, has been used in the treatment of refractory PDPH. Adrenocorticotropic hormone is believed to $\mathrm{w}$ by stimulating the adrenal gland to increase CSF productio and $\beta$-endorphin output. Caution should be used tient with diabetes. ${ }^{31}$

The serotonin type 1-d receptor ag effective in the treatment of PDPH, comple resolution of symptoms. ${ }^{32,33}$ The drug is expensivo, nd side effects include pain at the site of in ction and cho tightness. Caution must be used in trea. o pat nits with ischemic heart disease using sumatript? 32,33 trolle cials are needed to further evaluate the of of matrip for PDPH.

A trend away fro conerven management to the use of the blood patch has $a_{1}$ eared in recent years. This is based on the relative ineffectivenoss of the conservative treatment. For example, over $80 \%$ of postpartum patients who are conservatively treated will still have a headache after 1 week.

\section{Epidural injections}

The autologous epidural blood patch (AEBP) has become the 'gold standard' in the treatment of PDPH. As there is some risk of infection when injecting blood into the epidural space, we will discuss the efficacy of some other aqueous agents that have been injected into the epidural space to treat PDPH. Prior to considering the use of epidural injections of blood or other substances to relieve the symptoms of PDPH, there needs to be a clearly negative history of sepsis and coagulopathy. HIV infection is not considered to be a contraindication to AEBP.

Dextran and $0.9 \% \mathrm{NaCl}$ (saline) injections into the epidural space transiently increase pressure in the epidural space, which subsequently decreases the leakage of CSF and restores subarachnoid pressure. ${ }^{34-36}$ Not only is the success rate moderate, but also anaphylaxis has been reported following the use of dextran for this purpose. ${ }^{35}$ Epidural patching with non-blood substances, eg, saline or colloid, are ineffective for prolonged relief, ${ }^{37}$ although other substances such as fibrin glue have been used. ${ }^{38}$ The utility of epidural morphine was investigated in one RCT. ${ }^{39,40,41}$ Epidural morphine $3 \mathrm{mg}$ was given after the end of a esthe and another $3 \mathrm{mg}$ was given on the following a This red ced the incidence of PDPH from $48 \%(1,25)$ to $2 \%(2,25)$, which translates to a statistically snific $t$ redu on in the relative risk of $0.25(0.08-0$ \%). 0 was respiratory depression, but nausea wa mericall, $\mathrm{v}, \mathrm{c}$ frequent in the morphine group (44\% versus $\cap \%, P=0.06)$.

\section{Atologou epidural blood patch (AEBP)}

T. AEBP y as first described by Gormley in 1960 for use in PDPs, was later popularized by DiGiovanni et al. ${ }^{38,42}$ The as ted mechanism of action of AEBP is tamponade of the dural leakage while simultaneously raising the subarachnoid pressure. Elevation of subarachnoid and epidural pressures remains for only about 20 minutes. ${ }^{42} \mathrm{MRI}$ evidence confirms a mass effect after injection of epidural blood, with gradual resolution over about 7 hours. Unlike saline, dextran or other fluids, blood is not removed quickly from the epidural space, ${ }^{43}$ and it potentially exerts a tamponade effect for much longer periods of time. The autologous blood is thought to form a fibrin clot over the dural rent, allowing CSF volume and hence pressure to normalize as new CSF is generated. ${ }^{44}$

Abouleish et al, summarized 524 cases of AEBP reported by eleven centers. ${ }^{45}$ Persistent symptomatic relief of PDPH following epidural blood patch was $>95 \%$, particularly when using volumes of blood $>15 \mathrm{~mL}$. In this review, using volumes of blood greater than $20 \mathrm{~mL}$ offered no advantages, as it is known that $20 \mathrm{~mL}$ spreads about 9-10 spinal segments when administered to patients in the sitting position. ${ }^{12}$

Some studies have demonstrated lower success rates, with only $61 \%-75 \%$ of patients demonstrating sustained benefit. These lower success rates may reflect dural puncture occurring with large-bore epidural needles versus smaller-gauge spinal needles. ${ }^{44,46,47}$ In obstetrical studies, the success rate 
of epidural blood patching for PDPH is lower because the dural hole made by 18 gauge Tuohy needles results in a large leakage of CSF, necessitating a second blood patch in as many as $29 \%$ of patients. ${ }^{34,47}$

\section{The technique of AEBP}

The procedure is performed only after a careful history to exclude other causes of headache. While some authors have recommended the administration of prophylactic antibiotics for the procedure, they are generally not used. Rarely, if fluoroscopy is being utilized, the prone position may be selected. The preferred interspace for injection is the one below the previous injection site, because blood preferentially rises cephalad following its injection into the lumbar epidural space. ${ }^{43,48}$ Usually, at least $20 \mathrm{~mL}$ of blood are aseptically withdrawn. In children, $0.2-0.3 \mathrm{~mL} / \mathrm{kg}$ of blood is needed. Phlebotomy should be attempted after first identifying the epidural space to avoid clotting. The blood is carefully, and aseptically, transferred to the anesthesiologist, who injects it slowly through the epidural needle until one of the following endpoints occurs: (a) complaint of back pain, neck pain or radicular pain in the leg or worsening headache during the performance of the epidural injection, or (b) once at least $20 \mathrm{~mL}$ have been successfully injected without complaint by the patient. The patient is advised to avoid straining, bend or heavy lifting for 2-3 days to allow the dural hole to hea

In regard to the optimum volume of autologe oro to be injected epidurally, Taivainen et al found th using $0 \mathrm{~mL}$ standard in all patients was equivalent to variably administered based upon height. ${ }^{46} \mathrm{O}$, s have a rocated more generous volumes. Crawford found at $20 \mathrm{~mL}$ was associated with $96 \%$ success versus $70 \%$ s. cess using 6-15 mL. ${ }^{51}$ The ideal time sper orm an epidural blood patch is within 24 hours unch e. ${ }^{50} \mathrm{Tr}$.ment failure after blood patching may cflect contis a transdural leak; ${ }^{51}$ in this case, the blood tch onoum repeated while keeping the patient flat for 24 ho rs afterwards to reduce the flow of CSF through the dural rent.

Complications following AEBP include the following: backache $(35 \%)$, neck pain $(0.9 \%)$, and transient temperature elevations (5\%) lasting 24-48 hours. Bleeding, infection, repeat dural puncture, and arachnoiditis from blood injected into the subarachnoid space have been reported. There have been at least two cases of facial nerve paralysis reported following autologous blood patch, both of which resolved spontaneously. Lowe and McCullough suggested that the etiology is ischemia of the 7th nerve resulting from decreased blood supply after an increase in intracranial pressure due to the injection of blood in the epidural space. ${ }^{52}$ There has also been at least one case of intractable dizziness, vertigo, tinnitus and ataxia. ${ }^{53,54}$ Blood patching has occasionally been associated with vasovagal syncope. ${ }^{55}$

\section{Prophylactic blood patch}

Some have suggested that blood patching be performed as a prophylactic measure (ie, prior to the development of a headache) in cases of unintended dural puncture occurring after the insertion of 17-18 gauge epidural needle into the subarachnoid space, particularly when there has been loss of considerable quantities of CSF. To date, there have been no large, prospective studies to advocate this practice, although some anesthesia practitioners still use it. Existing studies regarding prophylactic epid at bu d patch are limited by small patient numbers. ${ }^{56}$, Ylso, ther have been limitations suggested by the sm volus of 1 ood injected in some reviews. ${ }^{58}$ If one hoos to po orm prophylactic AEBP, some caveats are der; 9 should avoid prophylactic AEBP im riately for $w$ local anesthetic (LA) epidural top-off cose ac inistration, because the resultant high epidy rpsessure has sulted in at least one case of total spinal bck. ${ }^{59}$ Als the presence of LA in the epidural space may th retically nterfere with subsequent blood clot formation. ${ }^{60}$ Somo strongly advocated for prophylactic blood patch, a d larly if an epidural catheter is in place, they argue that it avoids the need for another epidural puncture, even though strong clinical evidence is lacking. ${ }^{37,61,62}$

\section{Prognosis}

Since PDPH is usually a self-limited condition, the prognosis is not significantly affected by treatment. The majority of headaches resolve within a week with conservative management (rest, hydration, symptomatic treatment) ${ }^{63}$ In an older study, $53 \%$ of headaches resolve in 4 days, $72 \%$ in 7 days, and $85 \%$ within 6 weeks. ${ }^{63}$ In a small minority of cases symptoms may persist for weeks, months, or even years. ${ }^{64}$ Rarely, the headache can become chronic with the longest reported headache after LP lasting 5 years. ${ }^{47,48,50,51}$ As PDPH begins to improve, headache severity decreases, patient mobility increases, and it takes longer for headache following postural changes to develop. ${ }^{52}$ It is unclear if patients with chronic headache or pain disorders experience more severe and/or prolonged PDPH.

\section{Conclusion}

Although not life-threatening, PDPH carries substantial morbidity by restricting activities of daily life. Current 
noninvasive treatments, including bed rest, fluids, analgesics, caffeine, and sumatriptan, only temporize the discomfort. ${ }^{33}$ Epidural blood patch remains the invasive treatment of choice, with approximately $70 \%$ prolonged success after initial injection. ${ }^{65}$ The benefit of prophylactic blood patching is not so clear but deserves consideration in those most at risk from a headache, such as the parturient, and after accidental dural perforation with a Tuohy needle. Surgical closure of the dural tear remains an option of last resort.

\section{Disclosure}

The author reports no conflict of interest in this work.

\section{References}

1. Reynolds F. Dural puncture and headache. BMJ. 1993;306(6882): 874-876.

2. Liu S, Carpenter RL, Neal JM. Epidural anesthesia and analgesia. Their role in postoperative outcome. Anesthesiology. 1995;82(6): 1474-1506.

3. Diaz JH. Epidemiology and outcome of postural headache management in spontaneous intracranial hypotension. Reg Anesth Pain Med. 2001;26(6):582-587.

4. Evans RW. Complications of lumbar puncture. Neurol Clin. 1998;16(1): 83-105.

5. Harrington BE. Post-dural puncture headache and the development of the epidural blood patch. Reg Anesth Pain Med. 2004;29(2): $136-163$.

6. Turnbull DK, Shepherd DB. Post-dural puncture headache: Pathogenesis, prevention and treatment. Br J Anaesth. 2003;91(5):718-729.

7. Lambert DH, Hurley RJ, Hertwig L, Datta S. Role of needle gauge tip configuration in the production of lumbar puncture headache. $K$ Anesth. 1997;22(1):66-72.

8. Strachan A, Train J. Lumbar puncture and heada As rating cerebrospinal fluid speeds up procedure. $\mathrm{Br}$ Med $1998 ; 31$ 7136): $1018-1019$.

9. Armon C, Evans RW. Addendum to assessy at: Preves on of postlumbar puncture headaches. Report of the $T$ entics and hnology Assessment Subcommittee of the Amencan Aca my of Neurology. Neurology. 2005;65(4):510-512.

10. Horlocker TT. Complications spina and epidural anesthesia. Anesthesiol Clin North Americ, 2000. (2):461-485.

11. Vandam LD, Dripps RD. Long-ter sow-up patients who received 10,098 spinal anesthet s, s) dromo of ceased intracranial pressure (headache and cular an auditory nticulties). J Am Med Assoc. 1956;161(7):586-5,

12. Gielen M. Post dural pu fure headache: a review. Reg Anesth. 1989; 14(3):101-106.

13. Norris MC, Leighton BL, Dessimone CA. Needle bevel direction and headache after inadvertent dural puncture. Anesthesiology. 1989; 70(5):729-731.

14. Reina MA, Dittmann M, Lopez Garcia A, van Zundert A. New perspectives in the microscopic structure of human dura mater in the dorsolumbar region. Reg Anesth. 1997;22(2):161-166.

15. Ready LB, Cuplin S, Haschke RH, Nessly M. Spinal needle determinants of rate of transdural fluid leakage. Anaesth Analg. 1989; 69(4):457-460.

16. Reina MA, de Leon-Casasola OA, Lopez A, De Andres J, Martin S, Mora M. An in vitro study of dural lesions produced by 25 -gauge Quincke and Whitacre needles evaluated by scanning electron microscopy. Reg Anesth Pain Med. 2000;25(4):393-402.

17. Keener EB. An experimental study of reactions of the dura mater to wounding and loss of substance. J Neurosurg. 1959;16(4):424-447.
18. Gormley JB. Treatment of post-spinal headache. Anesthesiology. 1960; 21:565-566.

19. Lybecker H, Djernes M, Schmidt JF. Post-dural puncture headache PDPH: onset, duration, severity, and associated symptoms. An analysis of 75 consecutive patients with PDPH. Acta Anaesthesiol Scand. 1995; 39(5):605-612.

20. Nishio I, Williams BA, Williams JP. Diplopia: a complication of dural puncture. Anesthesiology. 2004;100(1):158-164.

21. Bader AM. Neurologic and neuromuscular disease in the obstetric patient. Anesthesiol Clin North America. 1998;16:459-476.

22. Maurer K, Bonvini JM, Ekatodramis G, Serena S, Borgeat A. Continuous spinal anesthesia/analgesia vs single-shot spinal anesthesia with patient-controlled analgesia for elective hip arthroplasty. Acta Anaesthesiol Scand. 2003;47(7):878-883.

23. Abram SE. Treatment of lumbosacral radiculopathy with epidural steroids. Anesthesiology. 1999;91(6):1937-1941.

24. Errando CL. Transient neurologic syndrome, transient radicular irritation, or postspinal musculoskeletal symptoms: Are we describing the same "syndrome" in all patients? Reg Anesth Pain Med. 2001; 26(2):178-180.

25. Mokri B, Atkinson JLD, Do $\mathrm{kW}$, Syndrome of orthostatic headaches and diffuse pach, eningeal gad inium enhancement. Mayo Clin Proc. 1997;72(5

26. McGrady EM, Fre water JV. $S_{1}$ al b ache - with no headache. Anaesthesia. 1

27. Thoennissen, $\mathrm{k} v \mathrm{H}$, Lang W, Domanovits H, Laggner A, Müllner Does bo est aft cervical or lumbar puncture prevent headac systemat new and meta-analysis. CMAJ. 2001; 165(N):131 316.

28. Fylaki A, Dntopoulos C, Andreopoulou K. Is early mobilization associated with lower incidence of postspinal headache? A controli trial in 69 urologic patients. Anaesthesiol Reanim. 1991; 16(6):375- 78 .

29. hornbe $y$ EA, Thomas TA. Posture and post-spinal headache. A controlled trial in 80 obstetric patients. Br J Anaesth. 1988;60(2): S-197.

30. Camann WR, Murray RS, Mushlin PS, Lambert DH. Effects of oral caffeine on post-dural puncture headache: a double-blind, placebocontrolled trial. Anesth Analg. 1990;70(2):181-184.

31. Carter BL, Pasupuleti R. Use of intravenous cosyntropin in the treatment of post-dural puncture headache. Anesthesiology. 2000;92(1): 272-274.

32. Collier BB. Treatment for post dural puncture headache. Br J Anaesth. 1994;72(3):366-367.

33. Carp H, Singh PJ, Vadhera R, Jayaram A. Effects of the serotoninreceptor agonist sumatriptan on post-dural puncture headache: report of six cases. Anesth Analg. 1994;79(1):180-182.

34. Hodgson C, Roitberg-Henry A. The use of sumatriptan in the treatment of post-dural puncture headache. Anaesthesia. 1997;52(8):808.

35. Stride PC, Cooper PC. Dural taps revisited. A 20-year survey from Birmingham Maternity Hospital. Anaesthesia. 1993;48(3): $247-255$.

36. Trivedi NS, Eddi D, Shevde K. Headache prevention following accidental dural puncture in obstetric patients. J Clin Anesth. 1993;5(1): $42-45$.

37. Barrios-Alcaron J, Aldrete JA, Paragas-Tapia D. Relief of post-lumbar puncture headache with epidural dextran 40: a preliminary report. Reg Anesth. 1989;14(2):78-80.

38. DiGiovanni AJ, Dunbar BS. Epidural injections of autologous blood for postlumbar puncture headache. Anesth Analg. 1970;49(2):268-271.

39. Duffy PJ, Crosby ET. The epidural blood patch: Resolving the controversies. Can J Anaesth. 1999;46(9):878-886.

40. Al-Metwalli RR. Epidural morphine injections for prevention of post dural puncture headache. Anaesthesia. 2008;63(8):847-850.

41. Crul BJ, Gerritse BM, van Dongen RT, Schoonderwaldt HC. Epidural fibrin glue injection stops persistent post-dural puncture headache. Anesthesiology. 1999;91(2):576-577. 
42. DiGiovanni AJ, Galbert MW, Wahle WM. Epidural injection of autologous blood for postlumbar-puncture headache. II: Additional clinical experiences and laboratory investigation. Anesth Analg. 1972;51(2):226-232.

43. Beards SC, Jackson A, Griffiths AG, Horsman EL. Magnetic resonance imaging of extradural blood patches: appearances from $30 \mathrm{~min}$ to $18 \mathrm{~h}$. Br J Anaesth. 1993;71(2):182-188.

44. Szeinfeld M, Ihmeidan IH, Moser MM, Machado R, Klose KJ, Serafini AN. Epidural blood patch: evaluation of the volume and spread of blood injected into the epidural space. Anesthesiology. 1986;64(6):820-822.

45. Abouleish E, Vega S, Blendinger I, Tio TO. Long-term follow-up of epidural blood patch. Anesth Analg. 1975;54(4):459-463.

46. Taivainen T, Pitkanen M, Tuominen M, Rosenberg PH. Efficacy of epidural blood patch for post-dural puncture headache. Acta Anaesthesiol Scand. 1993;37(7):702-705.

47. Safa-Tisseront V, Thormann F, Malassine P, et al. Effectiveness of epidural blood patch in the management of post-dural puncture headache. Anesthesiology. 2001;95(2):334-339.

48. Djurjuus HJ, Rasmussen M, Jensen EH. Epidural blood patch illustrated by CT-epidurography. Acta Anaesthesiol Scand. 1995;39(5):613-617.

49. Rosenberg PH, Heavner JE. In vitro study of the effect of epidural blood patch on leakage through a dural puncture. Anesth Analg. 1985;64(5):501-504.

50. Loeser EA, Hill GE, Bennett GM, Sederberg JH. Time vs success rate for epidural blood patch. Anesthesiology. 1978;49(2):147-148.

51. Crawford JS. Experiences with epidural blood patch. Anaesthesia. 1980; 35(5):513-515.

52. Lowe DM, McCullough AM. 7th nerve palsy after extradural blood patch. Br J Anaesth. 1990;65(5):721-722.

53. Ostheimer GW, Palahiuk RJ, Shnider SM. Epidural blood patch for postlumbar puncture headache. Anesthesiology. 1974;41(3):307-308.

54. Walpole JB. Blood patch for spinal headache. A recurrence and a complication. Anaesthesia. 1975;30(6):783-785.
55. Andrews PJ, Ackerman WE, Juneja M, Cases-Cristobal V, Rigor BML. Transient bradycardia associated with extradural blood patch after inadvertent dural puncture in parturients. Br J Anaesth. 1992; 69(4):401-403.

56. Colonna-Romano P, Shapiro BE. Unintentional dural puncture and prophylactic epidural blood patch in obstetrics. Anaesth Analg. 1989;69(4):522-523.

57. Quaynor H, Corbey M. Extradural blood patch - why delay? $\mathrm{Br} J$ Anaesth. 1985;57(5):538-540.

58. Palahniuk RJ, Cumming M. Prophylactic blood patch does not prevent post lumbar puncture headache. Can Anaesth Soc J. 1979; 26(2):132-133.

59. Leivers D. Total spinal anesthesia following early prophylactic epidural blood patch. Anesthesiology. 1990;73(6):1287-1289.

60. Tobias MD, Pilla MA, Rogers C, Jobes DR. Lidocaine inhibits blood coagulation: implications for epidural blood patch. Anesth Analg. 1996; 82(4):766-769.

61. Stevens RA. Neuraxis blocks. In Brown DL, editor. Regional Anaesthesia and Analgesia. Philadelphia: WB Saunders; 1996:352.

62. Cheek TG, Banner R, Sauster J he BB. Prophylactic extradural blood patch is effective. A pr miniary mmunication. Br J Anaesth. 1988;61(3):340-342.

63. Dripps RD, Vandam LP Long $\mathrm{rm}$ follow $\mathrm{p}$ of patients who received 10,098 spinal ane etics: fain to scover major neurological sequelae. J Am d Assog 954;15 o):1486-1491.

64. Lybecker $\mathrm{H}-\mathrm{Dj}$ s Schmirt J. Post-dural puncture headache (PDPH): set, dura sever, and associated symptoms. An analysis of 7 secutive pa with PDPH. Acta Anaesthesiol Scand. $1995,9(5): 6-612$.

65. Veria SB, Th as PS, Rosenbaum AE, Wasenko JJ, Fellows DG Magnetic resonancermaging of cerebrospinal fluid leak and tamponade effect of $k$ od patch in post-dural puncture headache. Anesth Analg. $1997 ; 84(3 ; 85-590$.

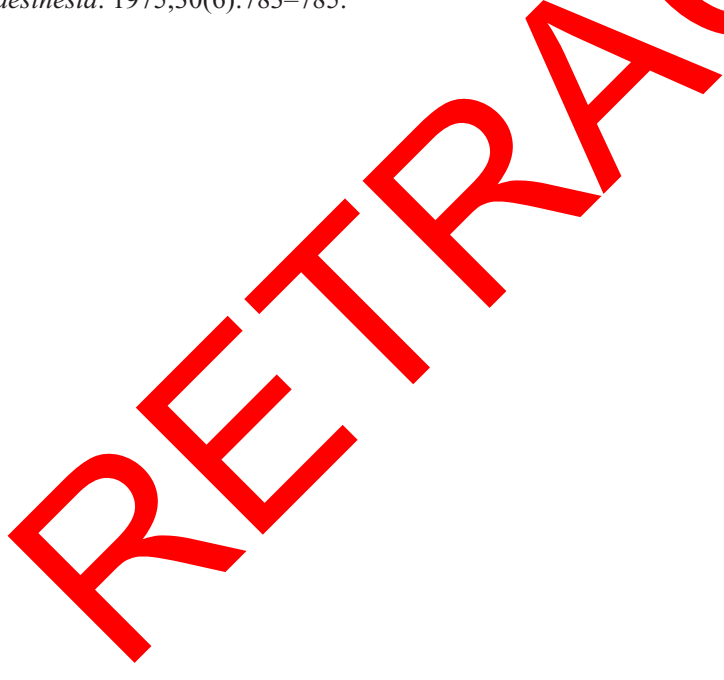

International Journal of General Medicine

Dovepress

\section{Publish your work in this journal}

The International Journal of General Medicine is an international, peer-reviewed open-access journal that focuses on general and internal medicine, pathogenesis, epidemiology, diagnosis, monitoring and treatment protocols. The journal is characterized by the rapid reporting of reviews, original research and clinical studies across all disease areas.
A key focus is the elucidation of disease processes and management protocols resulting in improved outcomes for the patient.The manuscript management system is completely online and includes a very quick and fair peer-review system. Visit http://www.dovepress.com/ testimonials.php to read real quotes from published authors. 